\title{
Un paso adelante, dos pasos hacia atrás. Las relaciones de Estados Unidos con Cuba bajo los presidentes Obama y Trump
}

Klaus Bodemer*

\section{RESUMEN}

Desde el triunfo de Fidel Castro en Cuba en 1959, las relaciones de Estados Unios con la isla caribeña fueron caracterizadas durante más de medio siglo por una alta hostilidad y conflictividad. Eso cambió durante el segundo mandato de Barak Obama con una serie de medidas que parecieron señalar el despegue de una nueva época de cooperación entre ambos países. Esa estrategia de descongelamiento de las relaciones bilaterales terminó, sin embargo, con la victoria electoral de Donald Trump y su estrategia favorita América first, que instrumentalizó de manera extrema la política externa para fines de la política interna. Para satisfacer a sus adherentes, entre ellos los cubanoamericanos en el Estado de Florida, Trump revertió paso por paso una gran parte de la política de apertura de su antecesor con efectos económicos negativos tanto para los cubanos como, aunque menos, para empresas y ciudadanos estadounidenses y empeoró sustancialmente la imagen de Estados Unidos y de su gobierno tanto en la región como en Europa. Un cambio generacional en la comunidad cubana en Miami, protestas de la Unión Europea y de ciertos sectores económicos en Estados Unidos despiertan por otra parte dudas si la política rígida de sanciones de la administración Trump sobreviva realmente a las próximas elecciones en Estados Unidos en 2020.

Como conceptos analíticos nos sirven el neorealismo, el socialconstructivismo y el concepto intermestic polictics.

Palabras clave: relaciones EE. UU.-Cuba, política de sanciones; Ley Helms Burton, América First, cubanoamericanos, Doctrina Monroe, COVID-19.

* Doctor, politólogo y profesor. Fue director del GIGA - Instituto de Estudios Latinoamericanos en Hamburgo. Desde 2018 es Independent Scholar, Berlin, Alemania. Correo electrónico: kbodemer@t-online.de

(iD) https://orcid.org/0000-0003-0101-1222 


\section{One step forward, two steps back. U.S. relations with Cuba under Presidents} Obama and Trump

\section{Abstract}

Since Fidel Castro's triumph in Cuba in 1959, relations between the United States and the Caribbean island have been characterized by a high level of hostility and conflict for more than half a century. That changed during Barak Obama's second term with a series of measures that seemed to signal the beginning of a new era of cooperation between the two countries. This strategy of thawing bilateral relations ended, however, with the electoral victory of Donald Trump and his favourite strategy "America first". In order to satisfy his supporters, among them the Cuban exiles in the state of Florida, Trump reversed step by step a large part of his predecessor's policy of openness with negative economic effects both for Cubans and, although less so, for American companies and citizens, and substantially worsened the image of the United States and its government both in the region and in Europe. A generational change in the Cuban community in Miami, protests from the European Union and from certain economic sectors in EEUU have also raised doubts as to whether the Trump administration's rigid policy of sanctions will really survive the next elections in the United States in 2020.

From the analytical point of view, we use approaches from neo-realism, social-constructivism and intermestic poltics.

Keywords: US-Cuba relations, sanctions policy, Helms Burton Act, America First, cubanamericans, Monroe Doctrine, COVID-19.

\section{Introducción}

Desde el triunfo de Fidel Castro en Cuba en 1959, durante más de medio siglo las relaciones de Estados Unidos (EE. UU.) con la isla caribeña se caracterizaron por una alta hostilidad y conflictividad. Después de una primera fase de acciones encubiertas contra Cuba y de la ruptura unilateral de relaciones el 3 de enero de 1961, Washington impuso el bloqueo. Este se extendió hasta tiempos recientes pese al rechazo explícito durante más de veinte años a esa política por parte de la comunidad internacional, a través de las Naciones Unidas. Uno de los intentos por aislar internacionalmente al régimen de La Habana, fue la expulsión de Cuba de la Organización de Estados Americanos (OEA). Ya entonces la mayor parte de las naciones latinoamericanas, a excepción de México, había roto relaciones diplomáticas con el régimen cubano.

El tema Cuba ha jugado un rol importante en las elecciones estadounidenses desde el comienzo de los años 1960. En 1996, el Congreso de los Estados Unidos aprobó la ley llamada Helms Burton Act que eliminó la posibilidad para ciudadanos estadounidenses de hacer negocios en Cuba o con el gobierno cubano. La política del embargo económico, defendida por sectores del exilio cubano en Miami, se mantuvo vigente 
más de medio siglo, el período más extenso que se conozca en la historia moderna. El Congreso de los EE. UU. ha complementado activamente la política de aislamiento durante todo este tiempo a través de medidas legislativas que alternativamente la han recrudecido y atenuado (CSR, 14 de mayo de 2020, p. 1). En las campańas electorales de los EE. UU. ha sido importante el peso de los votantes cubano-estadounidenses, aproximadamente un $7 \%$ del total.

A continuación me propongo analizar la política estadounidense hacia Cuba durante los gobiernos de Obama y de Trump atendiendo sus objetivos, instrumentos y resultados para preguntar cuáles entre ellos son elementos de continuidad y cuáles lo son de cambio. Finalmente haré una evaluación de cómo se relacionan las fuerzas políticas con miras a las próximas elecciones del 3 de noviembre de 2020, para inquirir si después de las elecciones sobrevivirá la restaurada política de endurecimiento hacia Cuba practicada en los cuatro años de presidencia de Donald Trump (2017-2020), o si, por el contrario, se retomará el proceso de normalización de dichas relaciones iniciado por Obama durante su segundo mandato.

Desde el punto de vista teórico, recurro a tres conceptos analíticos: el neorrealismo (Walz, 1990), el socialconstructivismo (Checkel, 1998; Wendt, 1999) y el de intermestic politics (Kurniawati, 2017). Trump percibe el mundo y actúa en los términos clásicos de Realpolitik. Categorías básicas de su estrategia América first que le sirve como hilo conductor tanto de su politica interna como exterior, son, como en la escuela realista, los terminos "poder» (Make America great again!), «interés nacional», "autonomía», «seguridad», la separación estricta entre amigos y enemigos y el escepticismo con respecto a la cooperación internacional, el multilateralismo y regímenes internacionales. La política exterior de Trump es además un ejemplo llamativo de «intermestic politics», un caso extremo de instrumentalización de la política exterior para objetivos internos, en el caso concreto: para satisfacer a su electorado y mantenerse en el poder. El socialconstructivismo nos ayuda, finalmente, a analizar los discursos y tweets de Trump, los valores y normas que constituyen la base de su pensamiento y su autopercepción.

\section{La herencia de Obama}

Ya antes de su elección como presidente, Barack Obama había dado muestras de estar dispuesto a modificar las relaciones con La Habana, poner fin a una política de sanciones vigente durante décadas e implementar paso a paso una política de normalización de las relaciones bilaterales. Otro factor prometedor de un paulatino descongelamiento de esas relaciones bilaterales había sido el tránsito operado desde el régimen cubano a una nueva época, desde que en 2006 Fidel Castro transfiriera el poder a 
su hermano Raúl Castro, proceso que tendría otro momento culminante en 2018 cuando este último abandonó de manera ordenada el gobierno para traspasar el poder político de la generación histórica de la Revolución, a una generación más joven.

En abril de 2009, en la V Cumbre de las Américas celebrada en Trinidad y Tobago, hubo un primer mensaje muy claro de los EE. UU. respecto a las relaciones bilaterales con el régimen socialista cubano. Allí Obama declaró que aspiraba a un «nuevo comienzo» con la isla y que para ello deseaba iniciar un proceso de negociaciones. Sus declaraciones tuvieron amplia resonancia a nivel regional e internacional. Así, cinco años más tarde, el 17 de diciembre de 2014, Raúl Castro y Barack Obama anunciaron en forma simultánea que iniciaban un difícil proceso de normalización de relaciones, el que incluiría estos tres pasos: primero, eliminar a Cuba de la lista de supuestos Estados patrocinadores de terrorismo, lo que ocurrió el 4 de junio de 2015; segundo, restaurar las relaciones diplomáticas, canceladas en 1961 por la administración Eisenhower, lo que se hizo en julio de 2015; y, tercero, implementar medidas para avanzar en el área de viajes, comercio y flujos de información hacia Cuba. Otros pasos fueron: la liberación de presos en ambos países, facilidades para el desarrollo de viajes turísticos, la autorización de actividades a empresas estadounidenses de telecomunicaciones e internet, de tarjetas de crédito y otros negocios financieros; $y$, finalmente, la autorización para importar determinados volúmenes de ron y de tabaco cubanos. En 2009, antes de implementarse estas medidas, los EE. UU. ya habían levantado un conjunto de restricciones para viajes y remesas familiares. A su vez, en 2011 se levantaron más restricciones que pesaban sobre viajes educacionales y religiosos y sobre remesas para personas no-familiares (CSR, 14 de mayo de 2020, pp. 1 y 21).

Obama contó para estos pasos con el apoyo de numerosas empresas estadounidenses, particularmente en los sectores turístico y agrícola. La reacción del Congreso en Washington a la nueva política fue mixta. Mientras algunos miembros aplaudieron el viraje, otros lo rechazaron. Si bien durante el $114^{\circ}$ Congreso de los EE. UU. en 2017-2018 hubo algunas iniciativas reflejo de tal rechazo, ninguna de ellas fue finalmente aprobada.

El 20 de julio de 2015 quedaron oficialmente restablecidas las relaciones diplomáticas entre ambos países. Muy pronto, incluso antes de esta señal histórica, peregrinaron a Cuba diversos líderes europeos: en mayo de 2015 lo hizo el presidente de Francia, François Hollande; en octubre, el primer ministro de Italia, Matteo Renzi; en marzo de 2016, el presidente de Austria, Heinz Fischer; y, poco después, el presidente de Portugal, Marcelo Rebelo de Sousa. Esas visitas fructificaron en la ampliación de las relaciones económicas entre las respectivas partes (Zeit, 8 de noviembre de 2017), lo cual puso fin a décadas de aislamiento del régimen castrista. La cesura 
política y el peso simbólico de la nueva política se reflejó también en la expresión «17 D», acuñada en Cuba para referir al 17 de diciembre de 2014, fecha de comienzo de una nueva reinserción de Cuba a nivel mundial (Hofmann, 2015, p. 3).

Numerosos acuerdos adicionales fueron negociados después de la reactivación de las relaciones diplomáticas entre Cuba y EE. UU., particularmente en las siguientes materias: áreas marítimas protegidas (noviembre de 2015), medio ambiente (febrero de 2016), servicio postal directo entre ambos países (diciembre de 2015), aviación civil (febrero de 2016), temas marítimos y de navegación (febrero de 2016), agricultura (marzo de 2016); salud (junio de 2016), lucha antidrogas (julio de 2016), meteorología (diciembre de 2016), sanidad de animales y plantas (enero de 2017), y fortalecimiento del Derecho (enero de 2017). En todas estas áreas se celebraron diálogos bilaterales, así como también en las áreas de derechos humanos, energías renovables y eficiencia energética, tráfico de personas y migraciones (CSR, 14 de mayo de 2020, pp. 21 y s). Finalmente, la administración Obama anunció en enero de 2017 otro cambio significativo: el abandono de la llamada política wet foot/dry foot que había regulado desde mediados de la década de 1990 el ingreso a los EE. UU. de miles de migrantes cubanos no autorizados. La base jurídica de dicha política había sido un acuerdo migratorio bilateral de 1995, según el cual aquellos migrantes cubanos capturados en el mar dirigiéndose a los EE. UU., eran devueltos a Cuba, mientras que los que hubiesen logrado arribar por tierra a los EE. UU., podían permanecer allí. El fin de esta política en 2017 determinó que los cubanos ingresados ilegalmente a los EE. UU. que no calificaran para la ayuda humanitaria, en lo sucesivo pasaran a ser devueltos a Cuba, su país de origen.

La nueva política de distensión no solo dio un gran empuje a las relaciones bilaterales, sino que modificó también las relaciones de Washington con toda América Latina, dado el alto valor simbólico de Cuba para todo el continente. El objetivo central de Obama fue superar el creciente aislamiento de los EE. UU. debido a los nuevos empujes del proceso de integración latinoamericana que significaron la creación de la Comunidad de Estados Latinoamericanos y del Caribe (CELAC) y la de la Unión de Naciones Suramericanas (UNASUR), para así volver a desempeñar una función importante en las relaciones hemisféricas (Hofmann, 2015, p. 2). Finalmente, la abstención de la Casa Blanca en noviembre de 2016 en la votación de la ONU sobre el embargo comercial contra la isla, si bien de carácter mayormente simbólico, supo transmitir a nivel mundial un claro compromiso de la administración Obama por normalizar los vínculos bilaterales (Alzugaray, 2018, pp. 9 y ss). Todo ello alentó un ambiente de optimismo en ambos países. Los sectores económicos esperaron de este acercamiento nuevos impulsos para negociar y crecer. Por su parte, los defensores del embargo se alinearon crecientemente a la defensiva. 
La apertura se tradujo en numerosas medidas de deshielo: se establecieron vuelos regulares entre ambos países, así como viajes de cruceros, con lo cual cientos de miles de ciudadanos estadounidenses visitaron la isla, y no pocos cubanos que se habían marchado, regresaron a su vieja patria esperanzados con la posibilidad de emprender pequeños negocios privados. Empresarios europeos mostraron un creciente interés por invertir en Cuba y se les convenció de que la normalización de las relaciones del régimen castrista con su vecino del norte les ayudaría notablemente en ese sentido. La Unión Europea (UE) apostó fuertemente por impulsar las relaciones diplomáticas y económicas con Cuba. A su vez, los vínculos de Cuba con Venezuela se redujeron y diversificaron, debido también a que los intercambios económicos entre ambos países sufrieron el impacto de la profunda crisis en Venezuela.

Gran parte de la estrategia de normalización de las relaciones bilaterales se canalizó en lazos entre ambos gobiernos. Se celebraron reuniones de alto nivel para el restablecimiento de las relaciones diplomáticas, la profundización de la cooperación en áreas de mutuo interés, así como para la observancia y protección del medio ambiente. También se dio espacio al diálogo franco en temas sensibles, como el respeto a los derechos humanos. De ese proceso de cinco negociaciones se arribó a dos resultados importantes: la cooperación de ambas partes en la lucha contra el terrorismo, y la finalización del trato migratorio privilegiado que recibían los cubanos que llegaban sin visa a los EE. UU. (Infolatam, 2017).

A solo dos días de la asunción de Trump, ambos países llegaron a firmar dos acuerdos más: primero, un pacto de colaboración en el salvamento aéreo y marítimo en el peligroso estrecho de Florida; segundo, un acuerdo jurídico sobre límites territoriales en el golfo de México.

Este cambio de rumbo de la Casa Blanca durante la presidencia de Obama fue también una reacción a una serie de acciones de reforma emprendidas previamente por el gobierno cubano, tales como la reducción del tamaño del sector público, un mayor margen de maniobra — si bien reducido- para el sector privado, la libertad de comprar y vender propiedades, un mayor acceso al internet y una mayor libertad de viajar. Todas estas medidas contribuyeron a un florecimiento del sector no estatal cubano, que registró un crecimiento notable en la cantidad de personas self-employed workers, que pasaron de ser 180000 en 2008, a 580000 en 2017 (Piccone, 16 de abril de 2018, p. 2).

A la expansión significativa de los lazos oficiales, se sumó la de aquellos entre actores no estatales, por ejemplo de científicos, estudiantes, empresarios y de otros ciudadanos que se beneficiaron de la mayor flexibilidad en las relaciones mutuas y en particular de los viajes directos entre ambos países. 
Estos diferentes pasos de acercamiento generaron en el segundo período presidencial de Obama un intenso proceso de intercambios, encaminado a establecer y/o ampliar la cooperación en temas de interés común, sobre todo de seguridad y de medio ambiente. Como consecuencia del total de veintidós acuerdos bilaterales finalmente celebrados, funcionarios de ambos países comenzaron a reunirse regularmente y a establecer relaciones de cooperación que favorecieron la confianza mutua. Una expresión simbólica de tal acercamiento fue indudablemente que Raúl Castro haya sido invitado a participar en la Cumbre de las Américas en Panamá en abril de 2015. En esa oportunidad el presidente Castro se encontró por primera vez personalmente con su homólogo estadounidense, quien habría de visitar oficialmente La Habana un año más tarde. A comienzos de 2017, al final de la era Obama, los intercambios en ambas direcciones se habían incrementado notablemente. Una sensación de haber superado la Guerra Fría en el Caribe se expandía entre los ciudadanos de ambos países.

A pesar de esos innegables progresos registrados en los últimos años de la administración Obama, y de que el líder demócrata había ganado las elecciones de 2012 contando con el 48\% de los votos cubano-estadounidenses y en 2016 perdió solo un pequeño porcentaje de ellos en favor de su rival republicano, lo cierto es que la política de Obama hacia Cuba no pudo resolver el nudo gordiano de las relaciones bilaterales, a saber: la existencia de extensas sanciones económicas, financieras y comerciales de más de medio siglo de antigüedad, año tras año condenadas por los países latinoamericanos y la comunidad internacional (Alzugaray, 2017, p. 216). Obama no pudo tampoco levantar la prohibición de los viajes turísticos para estadounidenses ni implementar programas de "promoción democrática» que estimulasen a la oposición en Cuba, ni tampoco retirarse la base naval de Guantánamo. Tampoco las relaciones comerciales avanzaron cuanto hubiese sido posible. Por otro lado, la reducción de algunas restricciones al comercio y a los viajes, llevó a la aparición de nuevas partes interesadas o stakeholders, agentes dispuestos a resistir cualquier retorno a la antigua política de hostilidad. Fueron muchos los empresarios estadounidenses claramente interesados en que los mercados se mantuviesen abiertos.

La opinión pública en EE. UU. apoyó decididamente las medidas de distensión, mientras también los grupos de mayor incidencia en la política exterior consideraron que los pasos dados por Obama constituían un aporte positivo a la seguridad nacional. Como acertadamente ha destacado Elier Ramírez Cañedo, las declaraciones de Obama y de sus asesores más cercanos, desde sus primeras señales de acercamiento a la isla en diciembre de 2014 hasta el final mismo del gobierno demócrata, mostraron claramente que con el nuevo rumbo respecto a Cuba su administración intentó hacer coincidir los objetivos políticos específicos que se proponen para Cuba, con otros, regionales y globales, en una estrategia integral que le permite ganar en 
todos los frentes. Una victoria más bien indirecta de la nueva política estadounidense hacia la isla fue la derrota o al menos el debilitamiento desde 2015 de los principales aliados estratégicos de Cuba en el hemisferio: el kirchnerismo en Argentina -elecciones de 2015-, Evo Morales en Bolivia — referendo—, el movimiento ALBA y el régimen de Nicolás Maduro en Venezuela, país este último que se ha transformado en un Estado fallido. Las medidas tomadas por el gobierno de Obama hacia Cuba privaron de cierta cuota de justificación a los líderes de la región posicionados contra la influencia estadounidense. La nueva estrategia de Washington apuntó a una política de cambio más amplia, enfocada a extender la influencia estadounidense a toda la sociedad cubana. Su lema fue el «cambio de régimen» a través de la reconciliación de la nación. Para ello, EE. UU. buscó minimizar la visibilidad de sus agencias en la isla y sustituirlas por "las manos de otros», esto es, la política de «change by the hands of others (Lancinski, 2015). Esta coincidía perfectamente con la Estrategia de Seguridad Nacional del año 2015 que promovía el principio de "paciencia estratégica», cuya intención era que las transformaciones en Cuba se diesen en forma natural y gradual mientras se eliminaban las posturas antagónicas de las relaciones bilaterales y con ello las reacciones de autodefensa (National Security Strategy, 2015).

Como se verá en los párrafos siguientes, la voluntad del presidente Obama contenida en su discurso de octubre de 2016 en La Habana, según el cual el proceso de distensión entre EE. UU. y Cuba habría de ser políticamente irreversible (The White House, 14 de octubre de 2016), no sobrevivió más allá de su gobierno, a pesar del signo indudablemente positivo del «legado» de la política hacia Cuba desarrollada en su segundo mandato.

\section{La marcha atrás instalada por Trump}

\subsection{Primeros pasos}

Cuba no ha había sido un tema central de ambos partidos en la campaña electoral de 2016, sin embargo, las diferencias programáticas al respecto eran muy marcadas. La plataforma demócrata anunció que seguiría en la línea de apertura iniciada por Obama (Democratic Party Platform Committee, 8-9 de julio de 2016). Hillary Clinton incluso ya antes de diciembre de 2014 llamó a abolir el embargo contra Cuba (Council on Foreign Relations, 12 de junio de 2014). La plataforma republicana, por su parte, denunció que la política de Obama hacia Cuba era de «una vergonzosa complacencia con los requerimientos de sus tiranos» (a shameful accommodation to the demands of its tyrants) y ofreció relaciones normales recién para «después que los corruptos gobernantes (de Cuba) hayan sido expulsados del poder y obligados a rendir cuentas por sus crímenes contra la humanidad» (after (Cuba's) 
corrupt rulers are forced from power and brought to account for their crimes against humanity) (Republican National Convention Committee on Arrangements, 2016).

Donald Trump presentó distintas visiones de Cuba durante su campaña. En las elecciones primarias fue el único candidato republicano que apoyó la apertura comercial. A finales de 2015 manifestó que cincuenta años habían sido suficientes (fifty years is enough) y agregó que consideraba acertada la apertura con Cuba y que incluso se podría haber logrado un mejor acuerdo (The concept of opening with Cuba is fine. I think we should have made a stronger deal) (Mazzei, 8 de setiembre de 2015). Unos meses después, en marzo de 2016, el candidato declaró en CNN que probablemente mantendría las relaciones diplomáticas (I think Cuba has a certain potential and I think it's OK to bring Cuba into the fold) (Diamand, 23 de diciembre de 2014). Esta posición se mantuvo inalterable hasta setiembre de 2016, cuando Newsweek publicó un artículo revelando que el candidato republicano ya en 1998 había explorado secretamente oportunidades de invertir en Cuba, ello en violación del embargo estadounidense, y que había después intentado encubrir esa actividad ilegal bajo la apariencia de un proyecto caritativo (Eichenwald, 29 de setiembre de 2016). Ya poco después, Trump abogó por una vuelta atrás, subrayó en su cuenta de Twitter que el pueblo cubano había luchado demasiado tiempo y prometió condicionar el proceso de normalización de las relaciones bilaterales emprendido por el presidente Obama, a avances en derechos humanos y libertades políticas en Cuba (Flores, 18 de setiembre de 2017). En la recta final de su campaña, Trump intentó ganarse el voto cubanoestadounidense de Florida, y para ello aseguró que sería firme en su oposición a los Castro. Prometió además que, de resultar electo, cerraría la embajada estadounidense en La Habana inaugurada por su antecesor. Ello finalmente contribuyó a su triunfo, por cuanto la imagen del apretón de manos de Obama con Raúl Castro en marzo de 2016 había sido un golpe considerable para los exiliados cubanos en Miami y sus familias. El vocero de Trump fue entonces el senador republicano Marco Rubio.

Pero, a la postre, el éxito que su coqueteo con los cubano-estadounidenses, los Cuban-Americans deparó a Trump no dejó de ser acotado, pues obtuvo solo entre el 52 y el $54 \%$ del voto cubano-estadounidense. Ello era apenas algo más que el obtenido por su rival demócrata Mitt Romney y mucho menos que el margen de 2:1 que los republicanos habían obtenido a su favor antes de 2012 (Mazzei y Nehamas, 9 de noviembre de 2016).

Los portavoces del gobierno cubano, por su parte, comentaron la campaña electoral y las elecciones estadounidenses con bastante cautela. Afirmaron que, quienquiera que resultase vencedor, Cuba esperaba que se respetara la voluntad del pueblo estadounidense, en su mayoría favorable a la normalización de las relaciones bilaterales (Gómez, 20 de julio de 2016). Raúl Castro felicitó a Donald Trump un día después 
de que este resultó electo, y el periódico cubano Granma citó a Trump con la frase conciliatoria: «We will seek common ground, not hostility; partnership, not conflict» (Granma, 10 de noviembre de 2016).

No obstante sus señales de que mantendría el camino de la normalización de las relaciones, uno de cuyos mayores logros habría de ser el levantamiento del embargo, tal política era resistida más allá de Trump también en el Congreso, donde los republicanos habían alcanzado en 2016 la mayoría en ambas cámaras. La pregunta central a partir de la victoria de Trump pasó a ser, por lo tanto, si el nuevo presidente pondría realmente en práctica los anuncios hechos en su campaña y si en consecuencia volvería a congelar las relaciones con la isla.

Una primera señal hacia una posición más dura del nuevo gobierno hacia Cuba fue el nombramiento por parte de Trump, para el equipo encargado de organizar la transición en el Departamento del Tesoro, de Mauricio Claver-Carone, fundador de un comité de acción política que defiende el embargo a Cuba, así como una de las voces más fuertes de la oposición a la política de acercamiento con Cuba. ClaverCarone tachó de servil la política de Obama hacia la isla (Infolatam, 2016). Pese a todo, no fue sencillo para Trump desmantelar y revocar los muchos componentes de la apertura, dados los múltiples canales de cooperación que ya estaban funcionando y el creciente interés en el lado cubano por recibir inversiones extranjeras en general, y de empresas estadounidenses en particular (Infolatam, 2016).

Una de las primeras voces antiembargo se conformó con el Latin American Working Group (LAWG) con sede en Washington. Este abogó por el mantenimiento de la política de cooperación y llamó a sus adherentes a establecer contactos con miembros del Congreso para exigirles su apoyo al mantenimiento de los viajes y de la cooperación con la isla. El LAWG hizo referencia a encuestas según las cuales el $81 \%$ de los estadounidenses en general y el $74 \%$ de los cubano-estadounidenses deseaban que se mantuviese la posibilidad de viajar a Cuba. Por su parte, el grupo de presión Engage Cuba, también favorable al acercamiento, intentó cuantificar los costos en lugares de trabajo y en dinero que tendría para los EE. UU. retirarse de los acuerdos. Según sus cálculos, volver a imponer las restricciones para viajes podría llegar a costar hasta 3500 millones de dólares y a afectar alrededor de diez mil puestos de trabajo en la industria turística en los siguientes cuatro años (Kornbluht, 2 de junio de 2017).

No obstante estas voces contrarias, Trump estableció claramente la marcha atrás en la política hacia Cuba ya pocos meses después de asumir su mandato. Anunció que evaluaría todos los acuerdos firmados con Cuba por la administración anterior, priorizando el tema de los derechos humanos, y manifestó su disconformidad porque el gobierno cubano no había hecho ninguna concesión a cambio de cuanto se le había 
regalado en el proceso de normalización de relaciones, en los acuerdos y en el trato diplomático. Pese a las varias advertencias sobre el daño que provocaría regresar a la política hacia Cuba previa a Obama, el 16 de junio de 2017 en una conferencia en Little Havana en Miami, el barrio y corazón simbólicos de los cubanos exiliados de la línea más dura, Trump incluso anunció una nueva política hacia Cuba promovida por Marco Rubio, senador de Florida y ex-rival de Trump en la campaña electoral, opuesta a los deseos del $63 \%$ de los cubano-estadounidenses que en las elecciones habían rechazado el embargo. Trump denunció entonces al régimen cubano como «brutal, criminal, degenerado, opresivo y sangriento» (The White House, 16 de junio de 2017).

Según la Oficina de Prensa de la Casa Blanca, la nueva política introducida por Trump estaba al servicio de cuatro objetivos: primero, mejorar el cumplimiento de la legislación de EE. UU., en particular las disposiciones que rigen el embargo sobre Cuba y la prohibición del turismo; segundo, responsabilizar al régimen cubano por la opresión y por abusos en derechos humanos, aspecto ignorado por la política de Obama; tercero, fomentar la seguridad nacional y los intereses de la política exterior de los EE. UU. así como los del pueblo cubano; y finalmente, cuarto, establecer bases de fortalecimiento del pueblo cubano en el desarrollo de condiciones de mayor libertad económica y política en la isla (s/a, 16 de junio de 2017). La nueva política incluyó la cancelación de transacciones financieras a muchas empresas vinculadas con la corporación Grupo de Administración Empresarial S.A. (GAESA) que opera docenas de hoteles y restaurantes en Cuba y según el gobierno estadounidense estaría vinculada al sector militar. La administración Trump revocó además visitas «de persona a persona» que habían estado autorizadas durante la administración Obama, y prescribió que los viajes no turísticos, como de académicos o de artistas, en lo sucesivo solo podrían realizarse en grupo. Estas medidas perjudicaron en primer lugar a los ciudadanos cubanos ocupados en el sector privado del turismo, quienes dependen económicamente del flujo de turistas para apoyar a sus familias (Superville y Weissenstein, 16 de junio de 2017). Las medidas dificultaron adicionalmente a los empresarios estadounidenses el hacer negocios en la isla (s/a, 16 de junio de 2017). Por otra parte, los cubano-estadounidenses seguían estando autorizados a visitar a sus familiares en Cuba y a enviarles remesas. También se autorizó que personas y entidades estadounidenses siguieran creando o desarrollando vínculos económicos con el sector privado en Cuba, particularmente pequeñas empresas.

A partir de su citada alocución del 16 de junio de 2017 en Miami, Trump retomó una política cuyo fracaso Obama había reconocido. Las medidas ordenadas por Trump reafirmaron el embargo de EE. UU. contra Cuba, contrariando las exhortaciones de las Naciones Unidas y de otros foros internacionales a darle fin. La nueva política 
exigió también informes periódicos sobre si en Cuba se avanzaba o no en sentido de una mayor libertad política y económica. Finalmente, Trump manifestó con claridad que cualquier mejora adicional en las relaciones bilaterales dependería exclusivamente de la voluntad del gobierno cubano de mejorar la vida del pueblo, el Estado de derecho, el respeto de los derechos humanos y la adopción de medidas concretas para aumentar las libertades políticas y económicas. Según algunos cálculos, las nuevas medidas expusieron a un conjunto de empresas estadounidenses a perder ingresos por más de 6000 millones dólares en los siguientes cuatro años (Biegon, 3 de julio de 2017).

La reacción del gobierno cubano ante los anuncios de Trump en Miami fue mayormente de moderación y pragmatismo. El canciller Bruno Rodríguez manifestó su rechazo a la nueva política hacia Cuba y advirtió que su país no negociaría bajo presión (La Nación, 19 de junio de 2017; Rhodes, 16 de junio de 2017). Granma, el órgano del Partido Comunista de Cuba, afirmó que la alocución de Trump en Miami estaba llena de una "retórica hostil» y constituía un "paso atrás en las relaciones bilaterales», así como el «regreso a una política fracasada» (Latin News, 22 de junio de 2017).

La respuesta relativamente moderada del gobierno cubano sin duda obedeció, como acertadamente han subrayado Susanne Gratius y Ana Ayuso (22 de junio de 2017), al hecho de que hoy ya no es posible aislar a Cuba como antes, dado que sus autoridades han diversificado sus relaciones exteriores tanto en la región (Canadá) como más allá (UE, China y Rusia), lo que significa que otros países están llenando el vacío dejado por Venezuela, socio estratégico desde los tiempos de Chávez y ahora atravesado por una gran crisis política y económica. A ello se agrega otro fenómeno, y es que tras la muerte de Fidel Castro en noviembre de 2016, Trump se encontró ante un dilema que Joaquín Roy, director de la Cátedra Jean Monnet de la Universidad de Miami, describió así:

Si opta por acosar a Raúl con exigencias drásticas que borren importantes concesiones de Obama, corre el riesgo de una respuesta nacionalista que haga peligrar la estabilidad de la zona. Si elige mantenerse prudente, traicionará sus promesas electorales. En cualquier caso, Raúl puede aparecer como ganador. (Roy, 27 de abril de 2016)

Pero también el gobierno cubano se encontró ante un cierto dilema, dado que el mantenimiento de las sanciones agudizó, por un lado, la crisis económica, pero le permitió por otro lado lograr que la población cerrara filas contra el enemigo del norte, al tiempo que implementaba (y legitimaba) medidas drásticas hacia dentro.

Raúl Castro ofreció a Trump mantener la cooperación pero le advirtió, sin embargo, no entrometerse en los asuntos internos ni cuestionar la soberanía de Cuba (Ganter, 
2017). Esta advertencia iba dirigida también al secretario de Estado Rex Tillerson, quien ya el 11 de enero de 2017, en su audiencia de confirmación en el Senado, había asegurado que Trump haría una «revisión de abajo hacia arriba» de las relaciones bilaterales con Cuba, incluyendo la decisión de Obama de retirar a Cuba de la lista de Estados patrocinadores del terrorismo (EFE, 8 de marzo de 2017). Algunos críticos del cambio de rumbo bajo la nueva administración republicana subrayaron que frenar el proceso de normalización iniciado por Obama arrojaría muchos perdedores, entre ellos algunas de las principales compañías estadounidenses, como American Airlines, Perdue Chicken y Starwood Hotels, empresas que ya habían comenzado a hacer negocios en Cuba, mientras otras, como Google y Caterpillar, estaban considerando realizar inversiones. Los más afectados serían, sin embargo, los pequeños empresarios cubanos que habían abierto restaurantes y establecimientos de hospedaje con desayuno, en muchos casos gracias al apoyo de familiares estadounidenses.

Las nuevas regulaciones extendieron además el círculo de aquellos con quienes se prohibía cooperar. Mientras las regulaciones dispuestas por el gobierno de Obama prohibían la cooperación con miembros del Consejo de Ministros y con altos rangos de las Fuerzas Armadas de Cuba, las disposiciones del gobierno de Trump incluyeron ahora a todos los empleados del Ministerio de las Fuerzas Militares Revolucionarias y del Ministerio del Interior, a las miles de personas que en Cuba trabajan voluntariamente ya como líderes de las Comisiones Locales para la Defensa de la Revolución, ya como funcionarios del Partido Comunista de Cuba. De ahora en adelante se prohibía enviar a estas personas dinero en forma de remesas, o paquetes de regalo desde EE. UU. El cambio de regulación más drástico fue la prohibición a los estadounidenses de participar en cualquier transacción financiera con empresas vinculadas a los militares y las fuerzas de seguridad cubanas, lo que afectó a un sinnúmero de bancos, comercios y agencias de turismo.

Un paso más hacia el endurecimiento de las relaciones con Cuba sería, el 10 de octubre de 2017, la expulsión de territorio estadounidense de quince diplomáticos cubanos y la reducción del personal diplomático estadounidense en La Habana, ello acompañado de una advertencia de la Casa Blanca a los ciudadanos estadounidenses para que no viajasen a Cuba. Ambas medidas fueron la reacción precipitada de Trump a los misteriosos «ataques sónicos» registrados en la embajada estadounidense en La Habana. Trump responsabilizó a Cuba por los ataques en momentos en que estaba aún en curso una investigación del FBI sobre el tema. La investigación buscó dilucidar el origen de los perturbadores sonidos (Mathus Ruiz, 18 de noviembre de 2017). Cabe destacar en este contexto que la American Foreign Service Association, la asociación de diplomáticos estadounidenses, se opuso a la reducción del personal diplomático en Cuba. Y que el origen de los misteriosos «ataques sónicos» se mantiene desconocido hasta hoy. 
La mayoría de los comentarios a la reducción del personal diplomático en ambos países fueron críticos, tanto en la prensa como en algunos think tanks estadounidenses. Se advirtió que con la nueva situación perderían tanto los cubanos como los estadounidenses (Camilleri, 24 de octubre de 2017). Harald Trinkunas y Richard Feinberg, del think tank Brookings Institution, previnieron contra la hostilidad creciente hacia Cuba, pues esta favorecería las corrientes anti estadounidenses y fomentaría una mayor acogida, por parte de Cuba y también de otros países de la región, a la influencia de los adversarios geopolíticos de los EE. UU., como Rusia y Venezuela ${ }^{1}$.

Una nueva ronda de conversaciones bilaterales tuvo lugar en diciembre de 2017. Ambas delegaciones confirmaron en ellas el levantamiento de la ya referida ley denominada de los «pies secos, pies mojados». Por otro lado, se acordó mantener el intercambio entre las tropas fronterizas de Cuba y las tropas costeras de los EE. UU., así como las conversaciones técnicas sobre el tráfico de personas y los fraudes migratorios (Göll, 2017).

No obstante esta serie de retrocesos, durante el primer ańo de la administración Trump, el cambio de la política estadounidense hacia el régimen castrista fueron parciales y bastante moderados. Varias cosas quedaron en su sitio. Trump dejó intactos una serie de acuerdos fundamentales que habían sido firmados durante el segundo período presidencial de Obama. Las embajadas de ambos países permanecieron abiertas, aunque con su personal sustancialmente reducido; se mantuvieron los vuelos comerciales directos por parte de algunas de las principales líneas aéreas estadounidenses: American Airlines, Jetblue y Delta. Lo mismo ocurrió con las compañías de cruceros, que siguieron operando, así como la plataforma de alojamientos Airbnb y gigantes tecnológicos como Google. Tampoco se devolvió a Cuba a la lista de países que apoyan a terroristas.

Entre los más afectados por las restricciones reintroducidas desde la Casa Blanca, estuvieron las instituciones académicas estadounidenses cuyos programas de becas corrieron el riesgo de sufrir sensibles recortes; aquellos ciudadanos estadounidenses a quienes se les prohibía ahora viajar con una licencia de "persona a persona»; ciudadanos cubano-estadounidenses cuyas familias en la isla ya no recibirían remesas ni paquetes de regalos; y, finalmente, los empresarios estadounidenses que se habían propuesto hacer negocios con contrapartes cubanas vinculadas al Ministerio de las Fuerzas Armadas Revolucionarias (LeoGrande, 9 de noviembre de 2017, p. 5).

\footnotetext{
1 Trinkunas y Feinberg, 2017, p. 2: «U.S. hostility risks damaging the coming transition to a new Cuban government after President Raúl Castro steps down in early 2018 by strengthening the hand of anti-American hardliners who oppose further economic opening on the island. It also damages U.S. relations with our partners in the region, who have long criticized what they see as senseless hostility between the U.S. and Cuba. Finally, the Trump administration's approach serves to widen the door to U.S. geopolitical adversaries, such as Russia and Venezuela, to advance their interests in Cuba and in the region».
} 


\subsection{El endurecimiento de las sanciones desde 2018. Sus efectos directos y colaterales}

Las relaciones bilaterales se endurecieron progresivamente a partir de 2018. En la política hacia Cuba Trump retornó a la estrategia de "cambio de régimen" aprobada con la ley Helms Burton del año 1996. La reorientación se dio con la consolidación de un equipo neoconservador en el entorno del presidente, con el ascenso de Mike Pompeo como secretario de Estado y de John Bolton como consejero de Seguridad Nacional. La prioridad de ambos hardliners fue satisfacer las demandas del exilio cubano intransigente en el sur de Florida y alinear la política estadounidense hacia la isla con los deseos de revancha y con las reclamaciones de propiedades por parte de ese sector. El vocero de esa fracción fue el senador Marco Rubio, responsable de la política hacia Cuba y Venezuela. Tanto Rubio como Bolton han criticado severamente al gobierno de los Castro. Bolton ya había intentado boicotear el viaje de Jimmy Carter a Cuba en 2002 y había acusado sin pruebas a Fidel Castro de desarrollar armas biológicas. En enero de 2018 Bolton escribió que la creciente intromisión de Rusia en América Latina y su estrecha cooperación con Cuba podrían inspirar a Trump para reconfirmar la vigencia de la Doctrina Monroe. Bolton manifestó sus dudas de que el régimen de Raúl Castro fuese a significar un real cambio en la isla, y recomendó sanciones más severas contra el gobierno cubano, no obstante el rotundo fracaso de la política de sanciones en el pasado. Marc Pompeo por su parte, apoyó al comienzo de la campańa electoral al candidato Marco Rubio, criticó severamente la visita de Obama a Cuba en 2016 y defendió el mantenimiento de la cárcel de Guantánamo. Marco Rubio, por último, apuntó conjuntamente con sus aliados en Miami y en el gobierno en Washington al colapso total del régimen castrista (Navarro, 20 de abril de 2018).

A menos de una semana de las elecciones intermedias de noviembre de 2018, John Bolton viajó a Miami para denunciar la «troika de los tiranos» conformada por Cuba, Venezuela y Nicaragua. Bolton calificó a los tres países como una amenaza que busca destruir la libertad hemisférica y de los EE. UU. El electorado de Florida, sin embargo, había cambiado su comportamiento ya en las elecciones de 2008. Ese año Obama obtuvo el 35\% de los votos cubano-estadounidenses, y con ello más que cualquier otro candidato demócrata con la excepción de Bill Clinton en 1996 tras la firma del Cuban Liberty and Democratic Solidarity Act, también conocido como ley Helms Burton. En las elecciones de 2012, Obama obtuvo alrededor de la mitad de los votos cubano-estadounidenses, una cifra nunca antes alcanzada por un candidato demócrata (Tamayo, 12 de noviembre de 2012). Finalmente, en diciembre de 2015, un año después del primer anuncio de apertura por parte de Obama, no menos del $56 \%$ de la comunidad cubano-estadounidense abogó por la normalización de las 
relaciones bilaterales y el 36\% en contra; el 53\% se manifestó a favor del levantamiento del embargo y el $31 \%$ en contra (Bendixen \& Amandi International, 2015).

De la mano de los tres políticos mencionados — Rubio, Bolton y Pompeo- regresó en 2018 la vieja obsesión republicana con el régimen cubano. En noviembre de 2018 la administración Trump amplió con 26 nombres adicionales, entre ellos varios hoteles, la lista de entidades cubanas con las cuales los estadounidenses tienen prohibido relacionarse. Así pasaron a ser más de 200 el número de entidades con las cuales están prohibidas las transacciones financieras directas de entidades y ciudadanos estadounidenses, a quienes se aplicaría una política de denegación de licencias de exportación y reexportación de bienes y servicios. También pasó a prohibirse por ley a los estadounidenses hacer turismo en Cuba (González Delgado, 15 de noviembre de 2018).

A pesar de las nuevas restricciones, en su visita a Nueva York en septiembre de 2018, Miguel Díaz de Canel, presidente de los Consejos de Estado y de Ministros de la República de Cuba, se reunió en la sede de Google, invitado por el exdirector ejecutivo de esa empresa Eric Schmitt, con ejecutivos de varias compañías como Twitter, Microsoft, Bloomberg y Cresta (s/a, 25 de setiembre de 2018). Por su parte, EE. UU. no regresó a la ley de "pies secos, pies mojados" que había sido derogada bajo el gobierno de Obama y favorecía la inmigración cubana irregular. Además, se mantuvo abierta una serie de canales de diálogo en temas de interés común, así como acuerdos bilaterales sobre cuestiones de seguridad y cumplimiento de la Ley. Los viajes turísticos, aunque formalmente prohibidos, se mantuvieron, bajo la forma por ejemplo de visitas entre familiares.

Es innegable que los nuevos pasos atrás afectaron negativamente la vida de miles de personas y sus familias en Cuba. Así, en diciembre de 2018 cerró su oficina local en La Habana el Servicio de Ciudadanía e Inmigración de los Estados Unidos (U.S. Citizenship and Inmigration Service, 10 de diciembre de 2018), con el efecto de que ese país incumplía así el acuerdo migratorio con Cuba según el cual debe entregar anualmente por lo menos 20000 visas para inmigrantes. A ello debemos añadir la ya mencionada extensión de la larga lista de entidades cubanas con las cuales los ciudadanos estadounidenses tienen prohibido relacionarse, de conformidad con el Memorándum Presidencial de Seguridad Nacional (González Delgado, 15 de noviembre de 2018). Voces cubanas agregaron a esta lista la retórica agresiva, sumada a la narrativa de los supuestos incidentes acústicos, factores que afectaron la imagen exterior de Cuba y pueden afectar negativamente el intercambio académico (González Delgado, 19 de diciembre de 2018, pp. 2 y ss).

En este contexto cabe mencionar que la política de sanciones, como otras políticas de Trump, no siempre fue coherente. Un ejemplo al respecto es que Trump firmase 
en diciembre de 2018 la Ley de Perfeccionamiento Agrícola, que incluye una disposición para permitir el uso de recursos estadounidenses en el mercado cubano. Esta medida fue tomada en un momento en que Trump había cambiado su política hacia Cuba e incrementado las estrategias de control económico, sobre todo en el turismo (Morales, 21 de diciembre de 2018).

Un paso más hacia el endurecimiento de las relaciones tanto con Cuba como con Venezuela se inició con las declaraciones del vicepresidente estadounidense Mike Pence el 5 de abril de 2019, según las cuales EE. UU. no cejaría en sus esfuerzos por liberar a Venezuela del control ejercido por el gobierno cubano: «The United States will continue to exert all diplomatic and economic pressure to bring about a peaceful transition to democracy. The time has come to liberate Venezuela from Cuba» (s/a, 19 de abril de 2019).

Argumentando que el gobierno cubano, liderado entre tanto por Miguel DíazCanel, se hallaba tras la política represiva del gobierno de Nicolás Maduro, y que los militares y el servicio secreto cubanos tenían una fuerte presencia en Venezuela, Mike Pence anunció nuevas sanciones contra aquellas compañías cuyos barcos transportasen petróleo venezolano a Cuba. El cálculo estadounidense fue con ello incrementar los costes para Cuba por seguir apoyando al régimen chavista, así como los costes para Rusia y China, ambos países interesados en defender sus intereses económicos y políticos en Venezuela. Un encuentro celebrado el 19 de marzo de 2019 entre el encargado estadounidense para Venezuela Elliot Abrams, y el viceministro de Relaciones Exteriores ruso Sergei Ryabcov, terminó sin arrojar resultados concretos.

La reacción del gobierno venezolano al anuncio de nuevas sanciones no se hizo esperar. Maduro anunció el 6 de abril que apelaría contra las nuevas sanciones con todos los instrumentos legales disponibles. Bruno Rodríguez, canciller de Cuba, las calificó «un acto de piratería«. Nuevamente fue el senador de Florida y asesor de Trump para Venezuela y Cuba, Marco Rubio, quien impulsó estas nuevas medidas, más allá de Abrams. El objetivo de ambos hardliners había sido «matar dos pájaros de un tiro", Venezuela y Cuba, como destacase el Latin American Security and Strategic Review: «bring down two birds with one stone» (s/a, 19 de mayo de 2019, p. 3).

Pocos días tras la declaración de Pence en abril de 2019, Trump emprendió una nueva ofensiva contra las inversiones extranjeras en Cuba. Reactivó la ley que permite a los ciudadanos de origen cubano llevar ante los tribunales a empresas cubanas para demandarlas por propiedades confiscadas tras la revolución de 1959. Así, el gobierno estadounidense omitió renovar la suspensión del Título III de la ley Helms Burton aprobada en 1996 bajo la administración de Bill Clinton. Durante dos décadas se había dejado este apartado sin efecto a través de suspensiones semestrales que iban 
aprobando todos los gobiernos para evitar el colapso en los tribunales, así como una batalla comercial con otros países. La nueva sanción, vigente por primera vez el 2 de mayo de 2019, abrió un nuevo frente entre EE. UU. y la UE, principal socio comercial de Cuba. El anuncio fue hecho por el secretario de Estado Mike Pompeo en una fecha simbólica, el aniversario de la invasión de bahía de Cochinos en abril de 1961, cuando tropas de exiliados cubanos llegaron a la isla con el apoyo del gobierno estadounidense para infructuosamente tratar de derrocar a Fidel Castro. Como efecto de la suspensión del Título III de la ley Helms Burton, se presentaron las primeras demandas de ciudadanos estadounidenses contra empresas internacionales por lucrar con propiedades confiscadas por el régimen castrista tras la revolución (Guimón, 3 de mayo de 2019).

En un paso más en ese sentido, John Bolton anunció, en un discurso en Miami ante veteranos de aquella operación fracasada de 1961, nuevas restricciones a las remesas de dinero enviadas a la isla, nuevas limitaciones para viajes de no familiares, así como medidas para evitar que los cubanos en lo sucesivo pudiesen sortear las restricciones y acceder a divisas (Mars, 5 de marzo de 2019).

Las nuevas medidas contra las empresas extranjeras en Cuba perjudicaron en primer lugar a empresas hoteleras españolas como Meliá, Iberostar, Barceló y $\mathrm{NH}$, todas con una importante presencia en la isla. Un efecto colateral de las nuevas sanciones fue que también obstaculizaron los esfuerzos diplomáticos no solo con Rusia y China, sino también con gobiernos latinoamericanos y con la UE a la hora de encontrar una salida a la situación de Venezuela. Las relaciones venezolanas con la UE ya se hallaban en un punto muy bajo desde que Bruselas reconoció a Juan Guaidó como presidente interino de Venezuela; algunos miembros de la UE empeoraron aún más la situación ante la amenaza de EE. UU. de tomar represalias contra inversores europeos en Cuba.

Washington implementó las nuevas medidas de presión contra Cuba como parte de una escalada de sanciones también contra Venezuela y Nicaragua, "la troika tiránica» en las mencionadas palabras de Trump. El 17 de abril de 2019, EE. UU. aprobó sanciones contra Laureano Ortega, hijo del presidente de Nicaragua, así como contra el Banco Corporativo de Nicaragua, cuyos activos en EE. UU. fueron bloqueados. También se procedió contra el Banco Central de Venezuela y contra Iliana Josefa Ruzza, una de sus directoras, negándoles el acceso al sistema financiero estadounidense por considerarles cómplices en el mantenimiento de Nicolás Maduro en el poder efectivo en Venezuela. Paralelamente, el secretario del Tesoro de los Estados Unidos Steven Mnuchin anunció nuevas medidas persecutorias contra las empresas navieras y los buques que transportasen petróleo a Cuba. Washington llegó a prometer que en el futuro no llegaría más crudo a la isla (Guerra Cabrera, 26 de setiembre de 2019). 
Una sanción más fue, finalmente, la decisión del Departamento de Estado de prohibir, a partir del 10 de diciembre de 2019, los vuelos a Cuba de las aerolíneas comerciales estadounidenses excepto aquellos hacia La Habana. Washington dio 45 días de plazo a las compañías American Airlines, JetBlue y Delta para que interrumpieran sus operaciones ya programadas en nueve de los diez destinos a los que volaban en Cuba. Este tipo de vuelos se había iniciado en 2016 cuando Barack Obama y Raúl Castro iniciaron el referido proceso de acercamiento entre sus gobiernos. Según portavoces del gobierno de Trump, la nueva medida se tomó para evitar «que el régimen cubano se beneficie de los viajes aéreos estadounidenses» y que ese beneficio sea usado "para financiar su represión contra el pueblo cubano y su apoyo a Nicolás Maduro en Venezuela» (BBC, 25 de octubre de 2019, p. 1). Pero la medida no afectó la modalidad de vuelos chárteres, mayoritarios en el mercado de viajes de EE. UU. a Cuba.

El gobierno cubano condenó fuertemente la medida por considerar que atentaba contra las libertades de los estadounidenses. Semanas antes, en setiembre, se habían implementado sanciones contra el expresidente de Cuba Raúl Castro y sus familiares. A comienzos de octubre, por su parte, entraron en vigor las limitaciones a los envíos de remesas a la isla (s/a, 19 de mayo de 2019, p. 2).

Resumiendo las diferentes medidas que el gobierno de Trump ha implementado contra Cuba desde las elecciones intermedias en 2018 hasta hoy, puede decirse que, pese a la dura retórica del nuevo presidente, los cambios en las relaciones bilaterales no han sido tan dramáticos como muchos temieron. Se mantuvieron las relaciones diplomáticas entre ambos países y sigue habiendo, aunque con personal reducido, una embajada cubana en Washington y una embajada estadounidense en La Habana. La ya mencionada política de "pies secos, pies mojados» que Obama había dejado sin efecto, se mantuvo así, en coincidencia con el objetivo de Trump de reducir la inmigración.

Entre los elementos de continuidad de la política estadounidense se cuenta, tanto para las relaciones con Cuba como con Venezuela, aunque sea en los discursos oficiales de la Casa Blanca, la democracia y la vigencia de los derechos humanos. Con respecto a esto último hubo ciertos avances en la isla. Según un informe del Congressional Research Service de 2020, en los años 2017 y 2018 se redujeron significativamente las detenciones a corto plazo por motivos políticos, en comparación con las registradas en el período 2010-2016 (CSR, 14 de mayo de 2020, p. 7). También ha habido avances evidentes en la libertad de expresión: si bien se mantiene un ambiente represivo sobre los medios de comunicación, en los últimos doce años han surgido multitud de blogs y de medios de comunicación independientes (CSR, 14 de mayo de 2020, p. 9). Estos avances modestos no impidieron que John Bolton endureciese su discurso respecto a la vigencia de derechos humanos y democracia en declaraciones hechas en Miami en noviembre de 2018. En su discurso, marcado por una retórica 
de confrontación propia de la Guerra Fría, dijo que Cuba, Venezuela y Nicaragua eran la «troika de la tiranía», «la causa de un inmenso sufrimiento humano», fuente de una enorme inestabilidad regional y «the genesis of a sordid cradle of communism in the Western Hemisphere» (The White House, 2 de noviembre de 2018).

Como reacción a la reactivación del Título III de la ley Helms Burton por el gobierno de Trump, la Comisión Europea ha amenazado por escrito al gobierno en Washington con una posible denuncia ante la Organización Mundial del Comercio (OMC). En carta dirigida a Mike Pompeo, la encargada de relaciones internacionales de la UE Federica Mogherini, y la comisaria de Comercio en la Comisión Europea Cecilia Malmström, subrayaron: «La Unión Europea se verá obligada recurrir a todos los instrumentos a su disposición en la cooperación con otros socios internacionales, para proteger sus intereses» (De Miguel y Mars, 17 de abril de 2019). Según este Título III, aprobado por la administración de Bill Clinton en 1996, es posible a los ciudadanos de origen cubano reclamar ante los tribunales estadounidenses las propiedades que les fueron confiscadas a raíz de la revolución de 1959 y que actualmente pueden hallarse en usufructo de inversores con intereses en Cuba. El Título permitiría una cascada de pleitos y nunca hasta ahora ha entrado en vigor. Ello obedece en parte a la presión de Bruselas en defensa sobre todo de los intereses de la gran presencia española en Cuba, en sectores como el hotelero (Sin autor, 19 de mayo de 2019, p. 2). La carta a Pompeo especifica claramente las posibles repercusiones de una reactivación del Título: «Si una cadena de hoteles estadounidenses [...] reclama (compensación) a una cadena europea ante tribunales de EE. UU. [...], la europea podría reclamar la misma compensación a la estadounidense ante un tribunal europeo», advertían las comisarias firmantes. El procedimiento, llegado el caso, permitiría confiscar bienes de las empresas estadounidenses también en el territorio de la UE, a fin de compensar a las empresas europeas perjudicadas. «Y hay que apuntar que la inmensa mayoría de los 50 mayores denunciantes, que suman el $70 \%$ del total del valor de las reclamaciones certificadas, tienen activos en la UE» (De Miguel y Mars, 17 de abril de 2019). La decisión de Trump con respecto al Título III, celebrada por el exilio cubano, formó parte de sus esfuerzos para propiciar un cambio político no solo en Cuba, sino también en Venezuela, dado el apoyo de La Habana al régimen de Nicolás Maduro.

\section{La política de la administración Trump hacia Cuba como una recaída en la Guerra Fría. Balance y perspectivas}

Como demuestran los párrafos anteriores, la voluntad política de la administración Trump de salvar por lo menos una parte del proceso de normalización de las relaciones bilaterales iniciado por Obama, ha disminuido progresivamente durante 
su presidencia. Tampoco en los primeros meses de este año electoral de 2020 se hicieron esfuerzos significativos por parte del gobierno estadounidense para rescatar las relaciones con Cuba de la actual espiral descendente. Todavía es incierto si Rusia y China ocuparán en Cuba el lugar antes ocupado por el país hermano Venezuela, muchos ańos el socio más importante y fiel de la isla. Mirando al futuro, lo único certero parece ser la incertidumbre. Trump en su presidencia ha quedado prisionero de un dilema político. Si hubiese cumplido con sus promesas electorales de borrar la política hacia Cuba implementada por Obama, y satisfecho así a la facción ultraconservadora de los cubano-estadounidenses, habría chocado contra la opinión pública mayoritaria en los EE. UU., así como con los cubano-estadounidenses moderados y con gran parte del sector empresarial estadounidense. Su lealtad a la derecha de los cubanos exiliados y su rígido abrazo al cambio de régimen en Cuba le han dificultado sobremanera alcanzar progresos en el camino de la normalización de las relaciones bilaterales y más bien han fortalecido el ala ultraconservadora también en la isla.

Al final de cuentas, las relaciones entre EE. UU. y Cuba son un buen ejemplo de la llamada intermestic politics, es decir, del estrecho relacionamiento entre la política interna y la exterior. El hecho de que Trump haya anulado algunas medidas implementadas por su antecesor, debe atribuirse en primer lugar a consideraciones internas, por ejemplo, al electorado en Miami y aquí en primer lugar a aquella facción ultraconservadora de cubano-estadounidenses representada por el senador republicano Marco Rubio. Este ex-rival de Trump en la campaña electoral republicana, se ha transformado durante la presidencia de Trump paulatinamente en uno de los más importantes asesores del presidente en asuntos hemisféricos, sobre todo en las relaciones con Cuba y Venezuela, ambas estrechamente interrelacionadas. Sin embargo, como demostraron sus votaciones tanto en 2016 como en 2018, esta facción conservadora dura representa cada vez menos al actual electorado cubano-estadounidense. La política de apertura de Obama había sido bienvenida tanto por una mayoría del electorado a nivel nacional, como a nivel de los cubano-estadounidenses moderados. Elocuente en ese sentido fue que CubaOne, una agrupación de jóvenes cubanoestadounidenses que busca reconectar a cubanos de la isla con aquellos emigrados, pocos meses después de llegado Trump a la presidencia, le enviase una carta abierta, rogándole que no volviese a las políticas de la Guerra Fría, las Cold War policies (Cuba Study Group, 12 de junio de 2017). Luego, en respuesta al anuncio por Trump de sus primeras medidas en ese sentido, la agrupación criticó que la nueva política perjudicaba al pueblo cubano y también los intereses estadounidenses (Morning Consult, 12 de junio de 2017; Cuba Study Group, 16 de junio de 2017).

Hoy, a pocos meses de las próximas elecciones en los EE. UU., surge la pregunta de si la línea dura sobrevivirá más allá de los cuatro años de la presidencia de Donald 
Trump. La respuesta no podrá ser un simple sí o no. Las principales motivaciones de Trump respecto a su política hacia Cuba tenían su origen en su deseo de liquidar el legado político de su predecesor Obama. Los misteriosos «ataques sónicos» registrados en la embajada estadounidense en La Habana, le dieron la oportunidad de revertir algunas de las principales medidas tomadas por Obama para impulsar las relaciones bilaterales. El discurso de Trump en Miami en junio de 2017 le sirvió para exponer ante los sectores más duros del exilio cubano las líneas principales de su política cubana. Sin embargo, con el correr del tiempo, la línea dura de la Casa Blanca se vio en crecientes dificultades ante voces críticas provenientes justamente de empresarios, del Congreso y de fuerzas moderadas entre los cubano-estadounidenses. El endurecimiento de las sanciones en abril de 2019 fue criticado tanto en el ámbito político como en el académico, y considerado un gran error porque le valió la antipatía de los socios europeos, contradijo los propios intereses estadounidenses y condujo a que Beijing y Moscú estrechasen más sus vínculos con $\mathrm{Cuba}^{2}$. Por último las nuevas sanciones incrementaron el riesgo de una crisis humanitaria en Cuba y generaron así las condiciones para nuevas migraciones masivas a noventa millas de la costa de Florida (Bill Chávez, 3 de mayo de 2019). No hubo una reacción de la Casa Blanca ante esas voces críticas. También después de las elecciones intermedias, que determinaron una mayoría demócrata en la Cámara Baja del Congreso, las relaciones bilaterales se mantuvieron en la situación de una espiral descendente, no obstante que Trump subrayó en una conferencia de prensa el 26 de septiembre de 2019 su voluntad de ejercer «máxima presión» contra el gobierno cubano también en 2020, con el fin de estrangular económicamente al sistema (Gámez Torres, 30 de setiembre de 2019).

Las consecuencias económicas de la política de sanciones son graves para la isla. Se ha debido racionar alimentos y productos de consumo diario que escasean, como huevos, arroz, pasta de dientes, jabón; el turismo ha disminuido un 8,5\% desde 2019, según cifras oficiales. Granma, el periódico del Partido Comunista de Cuba, tiene desde abril 2020 solo nueve páginas y no las acostumbradas dieciséis, debido a dificultades en la provisión de papel. En suma: el estado socialista caribeño se encuentra en su crisis económica más grave desde la década de 1990. Algunas de las causas existen desde hace décadas: una economía centralizada, el embargo estadounidense y la dependencia de Cuba respecto de las potencias hegemónicas. A estos elementos se suman algunos trastornos profundos relativamente recientes en el hemisferio occidental, como la caótica situación en Venezuela, país amigo de Cuba

\footnotetext{
2 El comercio entre Rusia y Cuba se ha más que duplicado desde 2013, y alcanzó en 2019 un monto por USD 500 millones. El 29 de octubre de 2019, en ocasión de la visita del presidente cubano Miguel Díaz-Canel a Moscú, ambos países suscribieron una serie de acuerdos y reafirmaron la vieja amistad y solidaridad entre ambos países (Rodríguez e Isachenkov, 2019).
} 
desde los años de Hugo Chávez, pero cada vez más claramente un Estado fallido; la victoria electoral de Jair Bolsonaro en Brasil y, sobre todo, la errática política de Donald Trump. Habían sido en primer lugar las buenas relaciones con Venezuela y con Brasil, lo que contribuyó a una fase de relativa estabilidad en Cuba tras la gran crisis de la década de 1990 desencadenada por el derrumbe de la Unión Soviética. El regreso a un gobierno de ultraderecha en Brasil, así como el colapso de la economía venezolana, eliminaron esos factores estabilizadores para Cuba.

El mantenimiento de las sanciones estadounidenses hacia la isla dependerá en el futuro no de la oposición a esa política dentro y fuera de los EE. UU., sino del resultado de las próximas elecciones presidenciales y parlamentarias del 3 de noviembre.

A consecuencia de la última ola de sanciones en octubre de 2019, el National Network On Cuba (NNOC), una agrupación de más de cincuenta organizaciones estadounidenses opuestas al embargo y demás sanciones contra Cuba, se reunió el 19 y 20 de octubre de 2019 para analizar la nueva situación y concertar una posible reacción. Los participantes de este encuentro oyeron una serie de informes sobre los impactos del bloqueo en la economía del país y en la vida cotidiana de la gente en Cuba. Alineándose con esta voz crítica, los parlamentos de dos de los estados de la Federación, Alabama y California, así como aproximadamente una docena de City Councils estadounidenses suscribieron una resolución exigiendo el fin de las sanciones y de las restricciones a los viajes hacia y desde Cuba. No hubo respuesta a ello por parte del gobierno en Washington, pero sí hubo un debate en el Congreso sobre la política de sanciones, y en 2019 se presentó un proyecto de ley que exige que los ciudadanos estadounidenses que deseen viajar a Cuba, tengan mucha mayor libertad de hacerlo: el Freedom for Americans to Travel to Cuba Act. Como bien apuntaba un observador, se requiere una movilización y una presión mucho mayores desde abajo, desde las bases populares, para que este proyecto de ley halle la necesaria mayoría en este período pre-electoral, lo que no se dio en los meses siguientes. Por otro lado, es evidente que la clase dirigente en los EE. UU. sigue estando dividida respecto al comercio con Cuba, y que una gran parte de ella está más interesada en ganar dinero ahora en el comercio con la isla, que en un futuro cambio del régimen (Schepers, 2019).

Resta señalar un último punto importante respecto al mantenimiento de las sanciones. Las votaciones en el estado de Florida, uno de los llamados «estados en disputa» o battleground states, jugaron y juegan un rol importante. Muchos afirman que, para salir vencedor en las elecciones presidenciales, Trump debería volver a ganar en Florida. Para ello argumentan que desde hace 95 ańos ningún candidato republicano ha ganado la presidencia sin haber ganado antes en Florida. En países donde se gana siempre con una pequeña mayoría, también pueden ser decisivos los votos de grupos pequeños como el de los cubano-estadounidenses, donde más de 
la mitad están registrados como republicanos. El resto se divide entre demócratas y un creciente grupo de «independientes» que deciden de manera flexible en cada elección a cuál de ambos grandes partidos respaldan. Últimamente ha sido posible identificar ciertos cambios en el comportamiento electoral de los ciudadanos de Florida. El grupo de población hispana o latinoamericana ha llegado a constituir en 2016 el $18 \%$ de la población total a nivel nacional. El incremento de este grupo se ha dado, sin embargo, de manera retardada. Sigue constituyendo el mayor grupo poblacional después del grupo de blancos de origen europeo. El 34\% de los hispanos o latinoamericanos son inmigrantes; los nacidos en suelo estadounidense eran en 2015 el 65,6\%, mientras en 2000 constituían el 59\% (Flores, 18 de setiembre de 2017). Se percibe, por último, un conflicto generacional entre los cubano-estadounidenses de más edad, llegados de Cuba en las primeras dos décadas tras la toma del poder por Castro, quienes hasta hoy se niegan a entrar en contacto con su vieja patria, y los más jóvenes, menos ideologizados y más deseosos de poder viajar a Cuba de cuando en cuando. Es sobre todo este último grupo el afectado por las sanciones de Trump, y el que se distancia crecientemente del comportamiento de sus mayores. Por ello no existe para las elecciones de noviembre ninguna mayoría pro-Trump garantizada entre los cubano-estadounidenses.

Los temas prioritarios para la mayor parte de la comunidad cubana en Florida, particularmente para los llegados después de 1993 a los EE. UU., son de tipo económico. Les interesa que se levanten las restricciones para viajar, que se garanticen los puestos de trabajo y que se regrese a la política de normalización de relaciones bilaterales comenzada por Obama en su segundo período presidencial. No desean, como tampoco lo desea la mayoría del resto de ciudadanos estadounidenses, un retorno perdurable a las condiciones de la Guerra Fría. Varias encuestas permiten apreciar desde la década de 1990 una tendencia creciente de apoyo a las políticas de apertura en el ámbito diplomático, de viajes y del comercio, particularmente entre los cubano-estadounidenses y los migrantes cubanos más jóvenes. Ello propició los logros diplomáticos entre Obama y Castro el 17 de diciembre de 2014 y condujo a que el 63\% de los cubanos en el condado de Miami-Dade opinasen en una encuesta de manera favorable al levantamiento del embargo y también al canciller cubano Bruno Rodríguez Parrilla.

Trump no parece disponer de una estrategia a mediano y largo plazo para las relaciones con la isla caribeña ni tampoco con otros países de la región. En realidad, la región no le interesa y suele decidir sus pasos más bien según su afán primordial de satisfacer a su electorado para mantenerse en el poder. Actualmente enfrenta la creciente ventaja de su rival Joe Biden del Partido Demócrata en las intenciones de voto, así como un descontento también en aumento de la población, incluso en 
estados con gobernadores republicanos, debido a su mal manejo de la crisis originada por el COVID-19. La campaña de Trump asume contornos de pánico y se hace crecientemente emocional y sucia, por cuanto en sus tuits y en los avisos televisivos el candidato se limita crecientemente a lanzar ataques personales a su adversario Biden. Los conservadores cubano-estadounidenses en el gobierno se esfuerzan en Washington bajo su líder Enrique Rubio por movilizar cuanto sea posible a sus adherentes ultraconservadores en Florida, y aparentemente tienen en ello cada vez más éxito. Como evidencia la mayor parte de las encuestas recientes, la política hacia Cuba no es un tema prioritario tampoco para los votantes cubano-estadounidenses. Ello significa que la oposición a la política cubana de Trump no necesariamente se traduce parcial ni totalmente en un apoyo a su adversario Biden. La explicación es que en la comunidad cubana en Florida no hay en realidad una oposición organizada contra la política de Trump hacia Cuba. El Partido Republicano ha demostrado contar en este estado con mayor fuerza que el Partido Demócrata. Finalmente, una encuesta de Equis Research de noviembre de 2019 sobre el comportamiento político de los cubano-estadounidenses en Florida, revela una fuerte intensificación de las tendencias existentes, y no su moderación. El 63\% de los votantes cubano-estadounidenses encuestados dijeron estar a favor de votar por Trump. Entre aquellos que inmigraron a los EE. UU. después de 1993, los favorables a la reelección de Trump fue aún mayor: el 73\% (Bustamante, 2020, p. 4). Estas cifras subrayan que hay pocas razones para esperar una oposición importante a la política cubana de Trump. Más bien parece probable que la votación de los cubano-estadounidenses sea este noviembre mayor que en 2016. Los más afectados por una nueva victoria de Trump serán aquellos inmigrantes cubanos post-1993 favorables a la normalización de las relaciones bilaterales.

Un último factor con efectos a mediano plazo poco previsibles para las relaciones de EE. UU. con Cuba, es la pandemia de COVID-19 que irrumpió meses atrás y sigue expandiéndose. El gobierno cubano prohibió ya el 24 de marzo el ingreso de turistas a la isla, cerró las escuelas y tomó una serie de medidas adicionales para reducir las actividades sociales y frenar la expansión de la pandemia. Se permitió el regreso desde el exterior a Cuba de aquellas personas que normalmente habitan en la isla y se les exigió guardar una cuarentena de dos semanas. Ya el 2 de abril el gobierno canceló todos los vuelos de y hacia la isla. Pese a que el manejo de la pandemia en Cuba exige los mayores esfuerzos por parte de sus autoridades, el gobierno cubano está prestando una ayuda importante en otros países en el combate de la epidemia de COVID-19. Más allá de la ayuda proporcionada por los equipos médicos cubanos en Venezuela, el gobierno cubano ha enviado equipos médicos, conformados por un total de 1500 personas, a varios países. Cuba tenía ya antes del estallido de la pandemia alrededor de 30000 profesionales médicos sirviendo en misiones sanitarias fuera de Cuba 
(CSR, 14 de mayo de 2020, p. 12). El llamado realizado al gobierno estadounidense por parte de Michelle Bachelet, alta comisionada de las Naciones Unidas para los Derechos Humanos, en el sentido de que levantase temporalmente las sanciones a Cuba para facilitar la entrega de ayuda humanitaria en la isla ${ }^{3}$ fue rechazado por la Casa Blanca con el argumento que las sanciones existentes ya permiten esa ayuda (CSR, 14 de mayo de 2020, p. 26).

Una serie de reformas aperturistas presentadas por el presidente cubano Miguel Díaz-Canel el 19 de julio pasado (2020) podría finalmente impactar de manera más sustancial en las relaciones bilaterales. El programa anunciado responde al brutal desabastecimiento de comestibles, al colapso de la industria turística y a la dramática disminución de divisas con la consecuente necesidad de importar bienes del exterior. Da un importante espaldarazo a la iniciativa privada, en tanto libera algunas fuerzas productivas hasta ahora sometidas al rígido control estatal y a la burocracia. El programa promete que se reconocerá personería jurídica a las pequeńas y medianas empresas (pymes). Según las nuevas disposiciones, las pymes estarán autorizadas a hacer negocios y a asociarse, tanto con empresas públicas como extranjeras, y tendrán la capacidad legal de importar y exportar. Se crearán mercados mayoristas y se pondrá fin al "experimento" realizado con las cooperativas no agropecuarias. Se anunció además una mayor flexibilidad y ampliación del trabajo por cuenta propia, sector en el que trabajan en Cuba ya 600000 personas, esto es el 13\% de la población empleada en el país. Además de estas reformas estructurales, se tomarán otras medidas urgentes a fin de paliar la grave falta de liquidez en moneda dura, entre ellas la eliminación del 10\% de gravamen con el que hasta ahora estaba penalizado el dólar, así como la apertura de mercados de comestibles y de diversos artículos de primera necesidad que solo podrán pagarse con divisas (Vicent, 20 de julio de 2020).

Si efectivamente se implementan estas medidas anunciadas, es probable que aporten a la normalización de las relaciones bilaterales entre EE. UU. y Cuba más que cualquier resultado de las elecciones de noviembre próximo.

\section{Referencias bibliográficas}

Alzugaray, C. (2017). La política exterior de Cuba en la era Trump. Pensamiento Propio, 45, 205-219. Recuperado de http://revistasnicaragua.net.ni/index.php/ pensamientopropio/article/view/3587/0

Alzugaray, C. (2018). Cuba y el gobierno de Trump. Foreign Affairs Latinoamérica, 18(1), 8-16.

Recuperado de https://wwww.academia.edu/.../Cuba_y_el_gobierno_de_trump

\footnotetext{
3 Véase: UN Human Rights Chief, 24 de marzo de 2020; UN Human Rights Chief, 30 de abril de 2020.
} 
BBC. (25 de octubre 2019). Vuelos a Cuba: Trump prohibe a las aerolíneas comerciales estadounidenses volar a la isla, con excepción de La Habana. BBC News Mundo. Recuperado de https://www.bbc.com/mundo/noticias-internacional-50147618

Bendixen \& Amandi International. (2015). Survey of Cuban-Americans: One Year After the Normalization of United States-Cuba Realtions. Miami.

Biegon, R. (3 de julio de 2017). Turning Back the clock on Cuba, ips-journal. http://www. ips-journal.eu/regions/latin-america/article/show/turnin

Bill Chávez, R. (3 de mayo de 2019). Trumps's Cuba Sanctions Are a Mistake. Tighening the failed embargo will push Havana into the arms of Beijing and Moscow. Foreign Policy. Recuperado de https://foreignpolicy.com/2019/05/03/ trumps-cuba-sanctions-are-a-mistake/

Bustamante, M. (2020). The cuban vote in 2020: Rejection of Trumpism or «somos continuidad»? El toque. Recuperado de https://eltoque.com/ the-cuban-vote-in-2020-rejection-of-trumpism

Checkel, J.T. (1998). The Constructivist Turn in International Relations Theory. World Politics, 50(2), 324-348.

Congressional Research Service - CRS (14 de mayo de 2020). Cuba: U.S. Policy in the 116th Congress. CSR Report. Recuperado de https://crsreports.congress.gov - R45657

Council on Foreign Relations. (12 de junio de 2014). Hillary Rodham Clinton on Strategic Interests, Values, and Hard Choices. Nueva York: Council on Foreign Relations. Recuperado de https://www.cfr.org/event/ hillary-rodham-clinton-strategic-interests-values-and-hard-choices

Cuba Study Group. (12 de junio de 2017). Letter by the Cuba Study Group to President Trump. The Cuba Policy Review. Recuperado de https:www.cubastudygroup.org/ index.cfm/newsroom?ContenRecord_id $=6 e e 53277-\mathrm{eab}=-4 \mathrm{a} 2 \mathrm{c}-8 \mathrm{~d} 8=-\mathrm{b} 2 \mathrm{~b}=\mathrm{d} 91 \mathrm{e} 9 \mathrm{ca} 4$ e7617c16\&MonthDisplay=1YearDisplay=2017

Cuba Study Group. (16 de junio de 2017). Statement by the Cuba Study Group Regarding the Conclusion of President Trump's Cuba Policy Review. Recuperado de http://cubastudagroup.org/index.cfm/newsroom?Content Record_id=21f9c4d3-5273-41f1-9975-aa1909b8f402\&ContentType_ id_=0c81d 17c-7ffe-48d6-81e7-cd93fe3120eb\&Group_ide=0b3ad3ec-d24e-4d2ab425-a97ae7617c16\&YearDisplay=2017

De Miguel, B., y Mars, A. (17 de abril de 2019b). Bruselas amenaza a EEUU con represalias si reactiva el castigo a los inversores europeos en Cuba. El Pais. Recuperado de https:// elpais.com/internacional/2019/04/16/actualidad/1555435009_882095.html

EFE. (8 de marzo de 2017). Cuba / EE.UU: Trump quiere concesiones de Cuba y ve deseo de una reforma migratoria en EEUU. Agencia EFE. Recuperado de https://www. efe.com/efe/america/politica/trump-quiere-concesiones-de-cuba-y-ve-el-deseo-unareforma-migratoria-en-ee-uu/20000035-3201718

EFE. (22 de febrero de 2018). Congresistas de EE. UU. piden a Trump mejorar relación con Cuba. La Estrella de Panamá. Recuperado de Laestrella.com.pa/internacional/ congresistas-eeuu-piden-trump-mejorar-relacion-concuba/ 
Eichenwald, K. (29 de setiembre de 2016). How Donald Trump's Company Violated the United States Embargo Against Cuba. Newsweek. http://www,newsweek. com/2016/10/14/donald-trump-cuban-embargo-castro-violated-florida-504059. html

Flores, R. (26 de noviembre de 2016). Fidel Castro's Death: Obama, Donald Trump React to Cuba's Leader Passing. CBS News. Recuperado de https://www.cbsnews.com/ news/fidel-castro-death-obama-donald-trump-react-cuba-leader-passing.

Flores, A. (18 de setiembre de 2017). How the U.S. Hispanic Population is changing. PEW Research Center. Recuperado de https://www.pewresearch.org/fact-tank//2017/09/18/ how-the-u.s-hsipanic-population-is-changing

Gámez Torres, N. (30 de setiembre de 2019). Trump readies new sanctions on Cuba; immigration policy likeley to main the same in 2020. Miami Herald. Recuperado de https:// www.miamiherald.com/news/nation-world/world/americas/cuba/article238826998. html

Ganter, S. (2017). ¿Qué bolá, Trump? Kuba nach Fidel Castro. Matices, 89(1), 5-8.

Camilleri, M. (24 de octubre de 2017). El deteriorio en las relaciones bilaterales con Cuba. Inter-American Dialogue. Recuperado de https://www.thedialogue.org/resources/ el-deterriorio-en-las-relaciones-bilaterales-con-cuba

Democratic Party Platform Committee. (8-9 de julio de 2016). Democratic Party Platform. Recuperado de http://s3.amazonaws.com/uploads.democrats.org/Downloads/2016/_ DNC_Platform.pdf

Diamand, J. (23 de diciembre de 2014). CNN/ORC Poll: Americans side with Obama on Cuba. CNN. Recuperado de http://www.cnn.com/2014/12/23/politics/cuba-poll/ index.html

Ganter, S. (2017). Que bolá, Trump? Kuba nach Fidel und Obama. Mátices, 1,5-8.

Göll, E. (2017). US-Regierung blockiert weitere Annäherung an Kuba, amerika21, 18.12. Recuperado de https://amerika21.de/2017/12/19124/usa-verschleppt annäherung

Gómez, S.A. (20 de julio de 2016). The Blockade Is an Outdated Policy and Must End. Granma. Recuperado de http://en.granma.cu/cuba/2016-07-20/ theblockade-is-an-outdated-policy-and-must-end

González Delgado, D. (15 de noviembre de 2018). Las prohibiciones se expanden: ¡solo sobre Cuba? Cubahora.

González Delgado, D. (19 de diciembre de 2018). Trump y Cuba en 2018: de la hostilidad a los hechos (Illustraciones). Cubahora. Primera Revista Digital de Cuba. Recuperado de http://www.cubahora.cu/politica/trump-y-cuba-en-2018-de-la-hostilida-a-los-hechos

Granma. (10 de noviembre de 2016). Raúl sends Message of Congratulations to Presidenteelect Trump. Granma. Recuperado de http//en.granma.cu/mundo/2016-11-10/raulsends-message-of congratulations-to-president-elect-trump

Gratius, S., y Ayuso, A. (22 de junio de 2017). Trump restaura la vieja política sin romper con Cuba. El Periódico. Recuperado de https://www.elperiodico.com/es/ opinion/20170622/trump-restaura-la-vieja-politica-sin-romper-con-cuba-6119041 
Guerra Cabrera, A. (26 de setiembre de 2019). Trump vs. Venezuela y Cuba. América Latina en Movimiento. Recuperado de https://www.alainet.org/es/articulo/202339

Guimón, P. (3 de mayo de 2019). Las demandas por confiscaciones en Cuba arrancan en EEUU- El Pais. Recuperado de https://elpais.com/internacional/2019/05/02/actualidad/1556819316_650598.html

Hakim, P. (2017). Cuba esté inquieta con la llegada de Trump, Confidencial, 24 de enero. https://confidencial.com.ni/cuba-esta-inquieta/.

Hofmann, B. (2015). Kuba-USA: Wandel durch Annäherung, GIGA Focus, Nr.2, 7 pag.

Infolatam.(22 denoviembrede2016). Trumpincluyeensuequipoodetransiciónaférreodefensor delembargoaCuba.Infolatam. Recuperadodehttp://www.infolatam.com/2016/11/22/ trump-incluye-en-su-equipo-de-trasición-a-ferrero-defensor-del-embargo-a-cuba

Infolatam. (18 de enero de 2017). Cuba y EEUU firman nuevos acuerdos antes de que asuma Trump. Infolatam. Recuperado de http://www.infolatam.com/2017/01/18/ cuba-eeuu-firman-nuevos-acuerdos-antes-de-que-asuma-trump

Kornbluh, P. (2 de junio de 2017). Trump Threatens to Rescind Obama's Cuba Engagement - and Activists Fight Back. The Nation. Recuperado de https:/www.thenation.com/ article/trump-threatens-rescind-obamas-cuba-engagement.

Kurniawati, D.E. (2017). Intermestic Approach: A Methodological Alternative in Studying Policy Change. PCD Journal, 5(1), 147-173. Recuperado de https://jurnal.ugm.ac.id/ $\mathrm{pcd} /$ article/view/26293

LaNación.(19dejunio2017).CubarechazanegociarbajopresiónconEstadosUnidos. LaNación. Recuperado de https://www.nacion.com/el-mundo/conflictos/cuba-rechaza-negociar-bajo-presion-con-estados-unidos/AWO6ERGD2VBOFBOVB6ODIXAPSI/ story/

Lancinski, P. (2015). Normalization of US-Cuban Realtions: Obama Doctrine and International Security in the Western Hemisphere. Securitología, 22(2), 5-16.

Latin News. (22 de junio de 2017). Trump's new Cuba policy: Tough Talk, soft substance. Latin American Weekly Report, 22 June-WR-17-24.

Latin News. (19 de abril de 2019). US intenisfies action against «CubaZuela». Latin American Security and Strategic Review, April- SSR-19-4.

LeoGrande, W. (9 de noviembre de 2017). Trump's New Cuba Sanctions. Miss Their Mark, Latin American Perspectives. Political Report 1292. http://americasquarterly.org/ content/trumps-new-cuba-sanctions-miss-their-mark.

Mars, A. (5 de marzo de 2019). Trump endurece el cerco sobre Cuba. El País. Recuperado de https://elpais.com/internacional/2019/03/04/estados_unidos/1551720765_009227. html

Mars, A. (17 de abrilde 2019). Trump emprende una gran ofensiva contra las inversiones extranjeras en Cuba. El País. Recuperado de http://elpais.com/internacional/2019/04/16/ estados-unidos/155

Mathus Ruiz, R. (18 de noviembre de 2017). Donald Trump responsabilizó a Cuba por los ataques a diplomáticos norteamericanos en La Habana. La Nación. Recuperado de http://www.lanacion.com.ar/2072747-donal-trump-responsabilizo 
Mazzei, P. (8 de setiembre de 2015). Donald Trump Says It's'Fine' for U.S.to Pursue Closer Cuba Ties. Miami Herald. Recuperado de http://miamiherald.com/news/politicsgovernment/election/article 34401528.html.

Mazzei, P., y Nehamas, N. (9 de noviembre de 2016). Florida's Hispanic Voter Surge Wasn't Enough for Clinton. Miami Herald. http://miamiharald.com/news/politics-government/election/article/113778053.html.

Morning Consult. (12 de junio de 2017). Cuba Engage Polling Presentation. ht tps://www.engagecuba.org/press-releases/2017/6/2017/ new-poll-6-in-10-republicans-support-policies-of-cuba-engagement.

Morales, B. (21 de diciembre de 2018). Trump da paso a productos agrícolas hacia Cuba. El nuevo día. Recuperado de https://www.elnuevodia.com/corresponsalias/cuba/notas/ trump-da-paso-a-productos-agricolas-hacia-cuba/

Navarro, B. (20 de abril de 2018). La contrarrevolución de Trump. La Vanguardia. Recuperado de https://www.lavanguardia.com/internacional/20180420/4427554...

Piccone, T. (16 de abril de 2018). Order from Chaos. U.S. Cuban relations are about to get worse, Brookings. Recuperado de https:/www.brookings.edu/blog/ order-from-chaos/2018/04/16/u-s-cuban-relations-are-about-to-get-worse/

Republican National Convention Committee on Arrangements. (2016). Republican Platform. Cleveland, Ohio, July 18-21.

Rodriguez, A., e Isachenkov, V. (2019). Putin hosts Cuban leader for talks on expanding ties. AP News, Moscow. Recuperado de https://apnews.com/ d2e58fa79c2f406c9c126c4cd46f4ef8.

Rhodes, B. (16 de junio de 2017). Trump's Cuba Policy Will Fail. The Atlantic. Recuperado de https://www.theatlantic.com/international/archive/2017/06/ cuba-trump-obama-opening/530568/

Roy,J.(27 denoviembrede2016). Cubatrasla muertedeFidel Castro. Infolatam, 27 denoviembre. http://www.infolatam.com/2016/11/27/cubanos-se-inquietan-sers-la-vida-sin-castro.

Scheppers, E. (23 de octubre de 2019). Opposition to Trump's anti-Cuba policy ar new high in U.S. Peoples World. Recuperado de https://peoplesworld.org/article/ opposition-to-trumps-anti-cuba-policy-at-new-high-in-u-s/

Sin autor. (16 de junio de 2017). La nueva política de EEUU hacia Cuba. Radio Televisión Marti. Recuperado de https:/www.radiotelevisionmarti.com/a/cuba-nueva-politicaeeuu-donald-trump/147068.html

Sin autor. (25 de setiembre de 2018). Díaz-Canel en Nueva York; Encuentro con ejecutivos de firmas tecnológicas. Cubahora. Primera Revista Digital de Cuba. Recuperado de https://www.cubahora.cu/ciencia-y-tecnologia/ diaz-canel-se-reune-con-ejecutivos-de-firmas-tecnologicas-de-ee-uu

Sin autor. (19 de mayo de 2019). Helms Burton Act becomes reality for Cuba. Latin American Caribberan\& Central America Report.

Superville, P. y Weissenstein, M. (16 de junio de 2017). President Trump Plans Rollback of Cuba Ties, Cutting Cash to the Military and Curbing Travel. Time. Recuperado de http://time.com/4821150/donald-trump-cuba-policy/-. 
Tamayo, J. O. (12 de noviembre de 2012). Did Obama or Romney Win the CubanAmerican Vote? Miami Herald. Recuperado de http://www.miamiherald.com/latestnews/article/1944516.html.

The White House. (2015). National Security Strategy. Recuperado de https://obamawhitehouse.archives.gov/sites/default/files/docs/2015_national_security_strategy_2.pdf

The White House. (14 de octubre de 2016). Statement by the President on the Presidential Poliy Directive on Cuba. Recuperado de https://obamawhitehouse.archives.gov/ the-press-office/2016/10/14/statement-president-presidential-policy-directive-cuba

The White House. (16 de junio de 2017). Remarks by President Trump on the Policy of the United States Towards Cuba. Recuperado de https://whitehouse.gov/the-pressoffice/2017/06/16/remarks-president-trump-policy-united-stetes-towards-cuba.

The White House. (2 de noviembre de 2018). Remarks by National Security Adviser Ambassador John R. Bolton on ther Administration's Policies in Latin America. Recuperado de https://www.whitehouse.gov/briefings-statements/remarks-nationalsecurity-adviser-ambassador-john-r-bolton-administrations-policies-latin-america/

Trinkunas, H., y Feinberg, R. (10 de octubre de 2017). Reckless hostility toward Cuba damages America's interests. Brookings. Recuperado de https://www.brookings.edu/blog/order-from-chaos/2017/10/10/ reckless-hostility-toward-cuba-damages-americas-interests/

UN Human Rights Chief (24 de marzo de 2020). Ease Sanctions Against Countries Fighting COVID-19. UN News. Recuperado de https://news.un.org/en/ story/2020/03/1060092

UN Human Rights Chief (30 de abril de 2020). Lift Cuba Embargo or Risk Many Lives Lost to COVID-19, UN Rights Warn US. UN News. Recuperado de https://news.un.org/ en/story/2020/04/1062982

U.S.Citizenshipand InmigrationService. (10 dediciembrede2018b).USCISCloses HavanaField OfficeonDec.10,2018.U.S.CitizenshipandInmigrationServices.https://www.uscis.gov/ es/noticias/alertas/uscis-cierra-oficina-local-de-la-habana-el-10-de-diciembre-de-2018

Vicent, M. (20 de julio de 2020). Cuba impulsa el sector privado en medio de la crisis del coronavirus. El País. Recuperado de https:/elpais.com/internacional/2020-07-20/ cuba-Iimpulsa-el-sector.

Walz, K. N. (1990). Realist Thought and Neorealist Theory. Journal of International Affairs, 44(1), 21-38.

Wendt, A. (1999). Social Theory of International Politics. Cambridge: Cambridge University Press.

Zeit. (8 de noviembre de 2017). Trump - Regierung dehnt Kuba-Sanktionen aus. Zeit online. Recuperado de https://www.zeit.de/politik/ausland/2017-11/ usa-kuba-sanktionen-aus

Recibido: 29 de enero de 2020

Aprobado: 24 de agosto de 2020 